\title{
Access to the Intensive Care Unit by Severe Head Injury Patients
}

\author{
James A. Balogun ${ }^{1,2}$ \\ ${ }^{1}$ Division of Neurosurgery, Department of Surgery, University of \\ Ibadan, College of Medicine, Ibadan, Nigeria \\ 2Department of Neurosurgery, University College Hospital, Ibadan, \\ Nigeria \\ ${ }^{3}$ Department of Anaesthesia, University College Hospital, Ibadan, \\ Nigeria \\ ${ }^{4}$ College of Medicine, Institute of Child Health, University of Ibadan, \\ Ibadan, Nigeria
}

J Neurosci Rural Pract 2019;10:666-671

\author{
Folusho M. Balogun 4
}

\begin{abstract}
Keywords

- severe head injury

- intensive care unit

- road traffic accidents

- access

- secondary brain injury

Background The management of severe traumatic brain injury is directed at avoidance of secondary brain injuries. The intensive care unit (ICU) provides the ideal environment to achieving improved survival and functional outcome. The study sets out to identify the factors that determine the access of patients with severe head injury presenting at our hospital, to the ICU and their impact on outcome.

Materials and Methods This was a longitudinal study at the University College Hospital, Ibadan. Data of all consecutive severe head injury patients over a 9-month period, presenting to the accident and emergency department, was collected and analyzed using descriptive statistics and chi-squared test. The level of significance was $p<0.05$. Result There were 36 males $(80.0 \%)$ in our study, with road crashes $(25 ; 79.5 \%)$ as the most common mechanism of injury. Most patients $(33 ; 73.3 \%)$ were transferred to our center after initial care in another hospital. Though $31(68.9 \%)$ patients had access to the ICU, they were all delayed, with the most common reason for the delay being lack of ICU space. More patients who got admitted into ICU $(14 ; 45.2 \%)$ were alive at 28 days into admission $(p=0.04)$. The females $(6 ; 13.3 \%)$ significantly survived till 28 days on admission compared with males $(p=0.03)$, but there was no difference in the survival rates between children and adults.

Conclusion Our study underscores the need for ICU admission in these patients to optimize outcome and identify the nonavailability of beds, as the most important cause of delayed access, as well as the need for increased manpower capacity and organized resource utilization.
\end{abstract}

\begin{abstract}
Address for correspondence James A. Balogun, MBBS, Division of Neurosurgery, Department of Surgery, Faculty of Clinical Sciences, College of Medicine, University of Ibadan, Ibadan, Nigeria (e-mail: jamesabalogun@gmail.com).
\end{abstract}

\section{Introduction}

Head injury constitutes a major public health problem and it is a leading cause of death following trauma. Approximately 10 million people were previously reported to have head injury yearly worldwide. ${ }^{1}$ However, a more recent review puts the global yearly prevalence of traumatic brain injury at 69 million with a prominent burden in the low- and middle-income economies. ${ }^{2}$ Head injuries are associated with a resultant high mortality, morbidities, and long-term or lifelong complications affecting movement, thought processes, language, emotions, memory, sensation, and communication that may require some form of support services for those affected.

While the exact prevalence of head injury in Nigeria is difficult to ascertain, several single institution studies have documented increasing prevalence, with the commonest mechanism in moderate and severe head injury reported to 
be road traffic accidents, especially among commercial vehicle drivers and motorcyclists, and predominantly involving individuals aged between 21 and 30 years. ${ }^{3-5}$ Males have been found to be at a higher risk of moderate-to-severe head injury and this was linked to their higher engagement in road transport activities than the females. ${ }^{6,7}$

The severity of head injury is evaluated using the Glasgow Coma Scale (GCS) grading such that a GCS score of 13 to 15 is regarded as mild, 9 to 12 as moderate, and 3 to 8 as severe. ${ }^{8}$ While mild injury has been identified as the commonest type of head injury, severe head injury has been associated with higher mortality and severe disability. ${ }^{3}$ In the United Kingdom, 11.0\% of hospital admissions for head injury have moderate-to-severe head injury, ${ }^{6}$ while in Nigeria, it is as high as $\sim 43 \%{ }^{9}$

Secondary brain injuries from systemic hypotension, hypoxia, hyperpyrexia, hypercapnia, hypoglycemia, or seizure can complicate and contribute to the extent of neurological injury. ${ }^{10}$ The clinical management of severe traumatic brain injury is therefore focused on the avoidance and treatment of secondary brain injury, with management guided by suggested guidelines, aimed at the maintenance of oxygen saturation $>90 \%$, systolic blood pressure of $>100$ to $110 \mathrm{~mm}$ $\mathrm{Hg}$, cerebral perfusion pressure between 60 and $70 \mathrm{~mm} \mathrm{Hg}$ and avoidance of hypothermia, hypercapnia, and early posttraumatic seizures. ${ }^{11,12}$ These treatment "cutoff" points are generally achieved in the context of the intensive care unit (ICU) and the quality of care provided determine the outcome of management. ${ }^{13}$

Neuro-ICUs, however, in developing countries are rare and expensive, ${ }^{14-16}$ particularly so within the context of low-income economies ${ }^{17}$ and it appears that a fully functioning ICU is an exception rather than the rule. ${ }^{18}$ Neurotrauma has to compete with other specialties for spaces in the ICU when available as major trauma accounts for the single most common reason for ICU admission with heavy financial, emotional, and physical burden to the family and even hospital resources. ${ }^{19}$

We sought to identify the factors that affect the access of patients with severe head injury to the ICU in our institution and to determine the impact of these factors on outcome among severe head injury patients presenting at the ICU at the University College Hospital (UCH), Ibadan.

\section{Materials and Methods}

\section{Ethical Consideration}

Ethical approval was obtained from the University of Ibadan/ University College Hospital ethics review committee. Written informed consent was obtained from the caregivers of the patients.

\section{Study Setting}

The study was performed at the UCH, Ibadan, a 900-bedded tertiary health care center, in southwestern Nigeria. It serves as the only tertiary referral center for the city of Ibadan, with a population of 3 million people, aside being the major neurosurgical referral center to the southwestern part of Nigeria and a large part of the country. The hospital has an accident emergency department, a dedicated neurosurgical department, a 10-bedded ICU with provision for ventilator support, and a usually available onsite emergency radiology. There are, however, no facilities for intracranial pressure monitoring yet. Severe head injury patients are received in the hospital's accident and emergency department, reviewed by the anesthesia team and admitted into the ICU as deemed necessary and according to availability of space.

\section{Study Design}

This was a prospective observational study. Patients with severe head injury (GCS $\leq 8$ ), without major injuries involving other systems, were recruited once admitted into the emergency department of the UCH, Ibadan, Nigeria.

\section{Data Collection Procedure}

The participants' data were recorded using a proforma by the neurosurgery residents once a patient was admitted into the emergency department and consented for the study. The information obtained includes the patients' biodata, time of injury, time of presentation at a hospital, duration of care at the hospital before presentation at $\mathrm{UCH}$, time of presentation at the hospital, time of first review, and time of anesthetist review as well as cause of delay. Data was also obtained regarding the GCS and blood pressure at presentation, brain stem reflexes present, pupillary size and reaction, CT scan findings, any immediate surgical intervention, time of ICU admission, time of commencement of ventilator support and reason for delay if any, date of ICU discharge, and GCS at ICU discharge.

\section{Data Management and Analysis}

Data was analyzed using Statistical Package for Social Sciences (SPSS) version 22. Outcome of the head injury was measured using the extended Glasgow outcome score, with a score of 1 representing death and a score of 8 indicating upper good recovery. Frequencies were generated and means and median were used to summarize variables that were normally distributed and those that were skewed, respectively. For example, the time from injury to presentation was skewed so median was used for the summary. Chi-squared test was used to test associations between categorical variables and likelihood ratio was reported whenever a cell has a value less than 5 . Associations between continuous variables like time were tested using independent $t$-test. The level of significance for all analyses was $p<0.05$.

\section{Result}

\section{Sociodemographic Characteristics of Participants}

There were 45 patients in the study with a male to female ratio of $4: 1$ and only $6(13.6 \%)$ patients were pediatric age (-Table 1).

\section{History of Accident and Transfer from Site of Injury}

The median time from time of injury to presentation in the hospital by those transferred directly from the accident scene was 4 hours (range: 1-11 hours), while for those who had 
initial care in another facility before presentation was 12 hours (range: $2-102$ hours) (- Table 2).

\section{Access to ICU}

The median time between the call for anesthetist review and actual review was 138 minutes (range: 0-3,010 minutes) and mean GCS at the review was $5.3 \pm 2.1$. Overall, 31 (68.9\%) patients had access to ICU, but there was delay in getting this access in all of them. The median interval between anesthetist review and arrival in ICU was 13 hours (range: $2-14$ hours). The most common reason for delay in ICU admission was nonavailability of bed space. Other reasons are as shown in - Fig. 1.

The mean stay in ICU was $11.2 \pm 9.3$ days and those who had cranial CT scan $(29,67.4 \%$ ) (-Table 3) were more likely to be admitted into ICU $(p<0.01)$. Also, those who were reviewed by the neurosurgery team within 24 hours were likely to be admitted into ICU $(p=0.03)$. The mean systolic blood pressure at presentation for those who had access to ICU was $12 \mathrm{~mm} \mathrm{Hg}$ higher than those who did not $(p=0.01)$

\section{Events in ICU}

Among the participants, 11 had surgery while on admission in the ICU ( - Table 4 ) and the decision to operate was taken before ICU admission in 10 (21.3\%) of them. Overall, only 8

Table 1 Demography

\begin{tabular}{|c|c|c|}
\hline Characteristics & Frequency (n) & Percentage (\%) \\
\hline \multicolumn{3}{|l|}{ Age } \\
\hline Child & 6 & 13.6 \\
\hline Adults & 38 & 86.4 \\
\hline \multicolumn{3}{|l|}{ Sex } \\
\hline Male & 36 & 80.0 \\
\hline Female & 9 & 20.0 \\
\hline \multicolumn{3}{|l|}{ Religion } \\
\hline Christianity & 21 & 44.7 \\
\hline Islam & 23 & 52.3 \\
\hline
\end{tabular}

Table 2 History of accident and initial care

\begin{tabular}{|l|l|l|}
\hline \multicolumn{2}{|l|}{ Frequency (n) } & Percentage (\%) \\
\hline Mechanism of injury & 10 & 22.7 \\
\hline Motorcycle & 9 & 20.5 \\
\hline Pedestrian & 6 & 36.4 \\
\hline Others & 9 & 20.5 \\
\hline Transferred directly from accident scene \\
\hline Yes & 12 & 26.7 \\
\hline No & 33 & 73.3 \\
\hline Intervention before presentation \\
\hline Yes & 8 & 22.9 \\
\hline No & 26 & \\
\hline
\end{tabular}

Abbreviation: RTC, road traffic collision.
(17.8\%) patients had enough financial capacity required to meet the demands for their treatment. The remaining had some delays in meeting up with the necessary obligations due to inadequate finance with 7 (15.6\%) and 29 (64.4\%) having some delay (4-12 hours) and gross delay ( $>12$ hours) in getting required funds. Being financially competent was not related to having access to ICU.

\section{Short-Term Functional Outcome Following Hospital Admission}

After 28 days of treatment, 29 (64.4\%) of the patients had died with 9 (20.0\%) in vegetative state and 5 (11.0\%) with low severe disability. There was a patient with upper severe disability and another with low moderate disability. The females (6; $13.3 \%$ ) significantly survived till 28 days on admission compared with males $(p=0.03)$, but there was no difference in the survival rates between children and adults. More of those who had some form of intervention before presentation $(7 ; 20.0 \%)$ also survived till 28 days $(p<0.01)$. Also, more patients who got admitted into ICU $(14 ; 45.2 \%)$ were alive at 28 days into admission $(p=0.04)$. The mean time interval from admission to death for those who had access to ICU was 9 days more than those who did not $(p<0.01)$.

\section{Discussion}

The guidelines for the management of severe head injury are aimed at reducing mortality and morbidity in addition to facilitating a return to normalcy for the patient as much as possible. The guidelines begin with the prehospital care of the patient, a resource that has been demonstrated to be remarkably deficient in our environment. ${ }^{20}$ This is further worsened by the delayed presentation of patients to the tertiary centers, where they can access appropriate specialist care, either due to delayed referral from the initial hospitals of presentation, long-distance hampering access to neurosurgical care, or lack of funds. ${ }^{7,21}$ The findings of our study corroborate the stated reasons, as only $26 \%$ of the patients were brought into the emergency room directly from the accident scene and this was mainly by relatives using personal cars or motor bikes. The median time of presentation following trauma was 4 and 12 hours for those transferred straight from the accident scene and those referred following initial treatments from other hospitals, respectively. These durations of time are rather long, considering evidence that delayed presentation and access to care are strongly associated with high mortalities. ${ }^{22}$ This is a further call for a more organized prehospital care and increased advocacy for early referral of head injury patients from government or privately-owned hospitals without neurosurgical expertise.

There is an interplay of factors varying from patients financial competence in a setting where out-of-pocket payment is predominant amidst prevalent poverty, to institutional factors which will include limited resources and personnel determine access of severe head injury patients into the ICU, such that in some limited resource countries, these patients are also admitted into the wards. ${ }^{23}$ We found unduly 


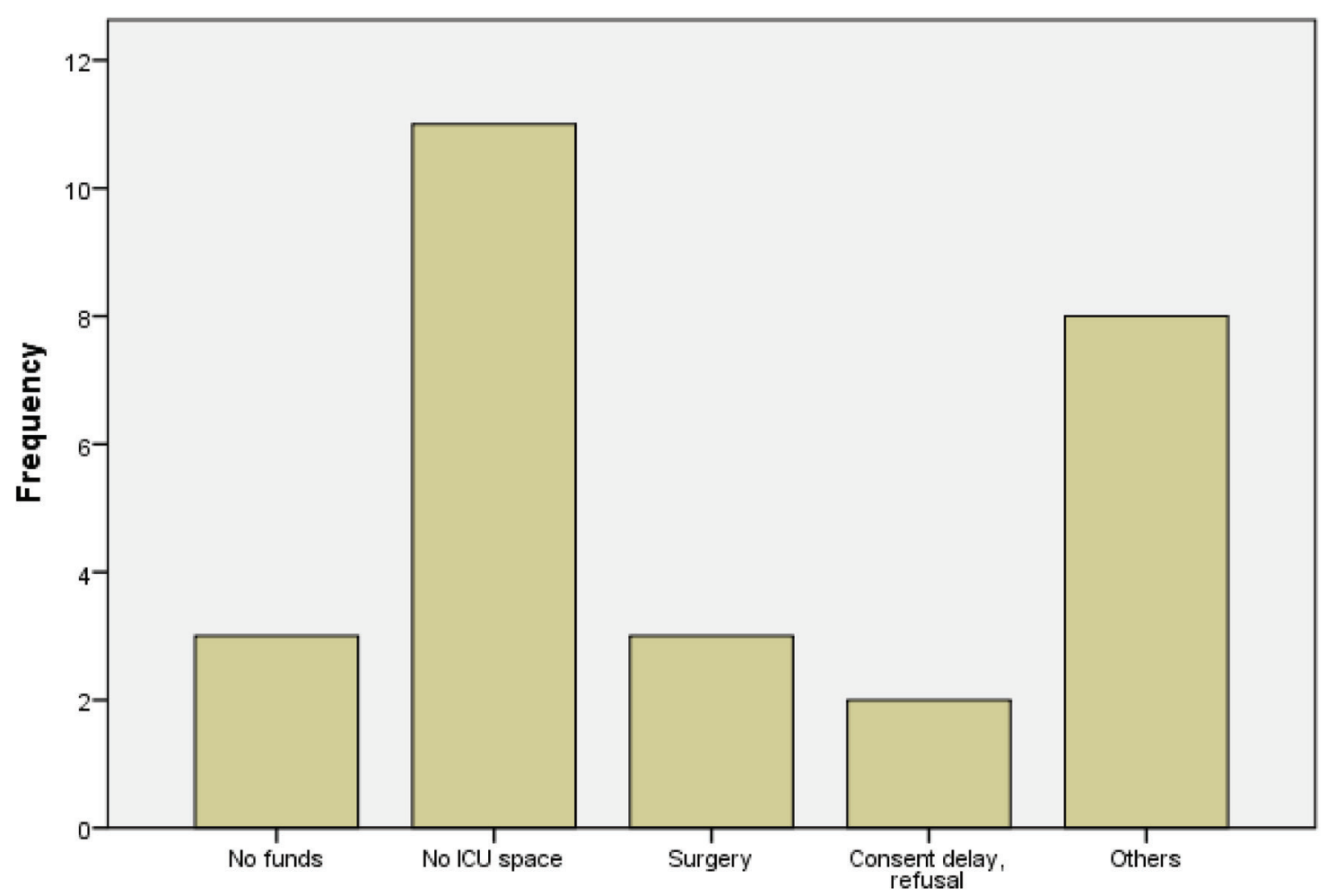

Reasons for delay in admission into ICU

Fig. 1 Reasons why patients with severe head injury had delay in admission to intensive care unit (ICU).

Table 3 Examination findings at presentation and investigation

\begin{tabular}{|c|c|c|}
\hline & Frequency $(n)$ & Percentage (\%) \\
\hline \multicolumn{3}{|l|}{ Pupils } \\
\hline Abnormal & 29 & 64.4 \\
\hline Normal & 16 & 35.6 \\
\hline \multicolumn{3}{|c|}{ Brainstem reflexes } \\
\hline Intact & 34 & 75.6 \\
\hline Not intact & 11 & 24.4 \\
\hline \multicolumn{3}{|c|}{ Cranial CT scan } \\
\hline Done & 34 & 79.1 \\
\hline Not done & 9 & 20.9 \\
\hline
\end{tabular}

Abbreviation: $\mathrm{CT}$, computed tomography.

long interval between when the anesthetist contact is made and the actual review of the patient, as well as between the anesthetist review and admission into the ICU. While third delay has been referred to as the time from arrival at the hospital to management by trained medical professionals, ${ }^{24}$ we surmise that since this is not the case in the delay from anesthesia review and consequently ICU admission, could this be a "fourth delay"? This "fourth delay" is attributable mainly to the lack of ICU bed space and only a small proportion of the patients were delayed due to a lack of funds. The delay in anesthesia review could also be due to the lack of an
Table 4 Treatment and medical complications

\begin{tabular}{|l|l|l|}
\hline Events in ICU & Frequency $(n)$ & $\begin{array}{l}\text { Percentage } \\
(\%)\end{array}$ \\
\hline Had surgical intervention & 11 & $35.5 \%$ \\
\hline Had ventilator support & 28 & 90.3 \\
\hline Medical complications & 24 & 77.4 \\
\hline Sepsis & 15 & 48.4 \\
\hline Pneumonia & 1 & 3.2 \\
\hline Urinary tract infection & 1 & 3.2 \\
\hline Others & 1 &
\end{tabular}

Abbreviation: ICU, intensive care unit.

organized neurocritical care team and paucity in manpower of the department of anesthesia, which is the specialty responsible for the general running of the ICU.

Time to neuroimaging of the patient also impacted on the possibility of being admitted into the ICU. This was important during the period of the study, due to the occasional periods when the hospital's CT scanner broke down, necessitating that the patient gets scanned in private facilities within the city.

Paradoxically, patients who were admitted into the ICU seem to have a higher mean systolic blood pressure at presentation than those who did not $(p=0.01)$. The hospital 
does not have a written guideline aside from clinical judgment of stratifying patients for ICU admission or restricting care to reduce what is defined as "nonbeneficial" treatment. This, we think, is more coincidental than deliberate.

Our study interestingly showed that the financial capacity of the patients/caregivers was secondary to the availability of an ICU space in determining access. This can be attributed to the deferred payment policy of the hospital especially for emergencies, which allows care to be administered prior to settlement of the bills. However, within the $68.9 \%$ of the patients that were admitted to the ICU, only $17.8 \%$ were able to promptly meet up with the financial obligation for the provision of their care. Thus, while financial competence did not impact on the admission of the patients into the ICU, the ability to continue to fulfil the obligation of care in a system that is heavily predicated on "out-of-pocket" payment did impact on the receipt of treatment by the patients. This may be partly responsible for the complications recorded in about half of the admitted patients.

Though the overall mortality in the study was $64.4 \%$ despite the delay in presentation and access to the ICU, there was a significant difference in the survival outcome between those admitted into the ICU and those who were not as more patients who got admitted into ICU $(14 ; 45.2 \%)$ were alive at 28 days into admission $(p=0.04)$. The import of ICU admission for this group of patients in our environment in spite the absence of noninvasive monitoring-which may have made further difference-is further supported by the fact that the mean time interval from admission to death for those who had access to ICU was 9 days more than those who did not $(p<0.01)$.

While one of the cardinal reasons for ICU admission in this cohort of patients is for ventilator support, only $62.2 \%$ of the patients were mechanically ventilated that is likely due to nonavailability of free mechanical ventilators. Thus, it appears that the presumed challenge of funds is not a barrier to ICU admission in our environment; access to the ICU bed by severe head injury patients revolves mainly around delayed review by the anesthesia team and the availability of bed space, which may by extension be impacted by the availability of mechanical ventilators.

This emphasizes a need for a set of institutional reforms, which will include the constitution of a neurocritical care team (even within the mixed medical and surgical ICU) that has been documented to improve the neurologic outcomes in severe head injury patients, ${ }^{25}$ the deployment of more mechanical ventilators as well as the effective use of a high dependency unit. A neurocritical team in a resource-challenged environment requires that the general need for manpower development be put into perspective. We, however, think that neurotrauma having assumed a public health top priority would deserve this attention.

\section{Limitations}

This is a single institutional study and thus bears the potential problem of an undue extrapolation to other centers within the country, which may not necessarily be challenged by the same issues.

\section{Conclusion}

Our study has documented the factors that influence the access of a cohort of severe head injury patients to the ICU in a low-income country and emphasizes the need for a guideline to direct and provoke an action toward a more organized system of neurotrauma care that can optimize available human resource, to limit the "fourth delay" review time and provide pre-ICU admission care within the limits of the available resources.

\section{Conflict of Interest}

None declared.

\section{Acknowledgment}

We appreciate the help of Dr Toyin Oyemalade and as well as of neurosurgery residents who helped out with data acquisition.

\section{References}

1 Hyder AA, Wunderlich CA, Puvanachandra P, Gururaj G, Kobusingye OC. The impact of traumatic brain injuries: a global perspective. NeuroRehabilitation 2007;22(5):341-353

2 Dewan MC, Rattani A, Gupta S, et al. Estimating the global incidence of traumatic brain injury. J Neurosurg 2019;130(4):1039-1408

3 Adeleye AO, Ogun MI. Clinical epidemiology of head injury from road-traffic trauma in a developing country in the current era. Front Neurol 2017;8:695

4 Solagberu BA, Ofoegbu CK, Nasir AA, Ogundipe OK, Adekanye AO, Abdur-Rahman LO. Motorcycle injuries in a developing country and the vulnerability of riders, passengers, and pedestrians. Inj Prev 2006;12(4):266-268

5 Idowu OE, Akinbo O. Neurotrauma burden in a tropical urban conurbation level I trauma centre. Injury 2014;45(11):1717-1721

6 Yates PJ, Williams WH, Harris A, Round A, Jenkins R. An epidemiological study of head injuries in a UK population attending an emergency department. J Neurol Neurosurg Psychiatry 2006;77(5):699-701

7 Malomo TA, Oyemolade TA, Adeleye AO. Determinants of timing of presentation of neurotrauma patients to a neurosurgical center in a developing country. J Neurosci Rural Pract 2018;9(4):545-550

8 Teasdale G, Jennett B. Assessment of coma and impaired consciousness. A practical scale. Lancet 1974;2(7872):81-84

9 Emejulu J, Isiguzo C, Agbasoga C, Ogbuagu C. Traumatic brain injury in the accident and emergency department of a tertiary hospital in Nigeria. East Cent Afr J Surg 2010;15(2):28-38

10 Helmy A, Vizcaychipi M, Gupta AK. Traumatic brain injury: intensive care management. Br J Anaesth 2007;99(1):32-42

11 Kochanek PM, Tasker RC, Carney N, et al. Guidelines for the Management of Pediatric Severe Traumatic Brain Injury, Third Edition: Update of the Brain Trauma Foundation Guidelines, Executive Summary. Pediatric critical care medicine: a journal of the Society of Critical Care Medicine and the World Federation of Pediatric Intensive and Critical Care Societies 2019 20(3):280-289

12 Carney N, Totten AM, O'Reilly C, et al. Guidelines for the Management of Severe Traumatic Brain Injury, Fourth Edition. Neurosurgery 2017;80(1):6-15 
13 McKeating EG, Andrews PJ, Tocher JI, Menon DK. The intensive care of severe head injury: a survey of non-neurosurgical centres in the United Kingdom. Br J Neurosurg 1998;12(1):7-14

14 Rhondali O, Genty C, Halle C, et al. Do patients still require admission to an intensive care unit after elective craniotomy for brain surgery? J Neurosurg Anesthesiol 2011;23(2):118-123

15 Beauregard CL, Friedman WA. Routine use of postoperative ICU care for elective craniotomy: a cost-benefit analysis. Surg Neurol 2003;60(6):483-489,489

16 Quimby AE, Shamy MC, Rothwell DM, Liu EY, Dowlatshahi D, Stotts G. A novel neuroscience intermediate-level care unit model: retrospective analysis of impact on patient flow and safety. Neurohospitalist 2017;7(2):83-90

17 Uche EO, Ezomike UO, Chukwu JC, Ituen MA. Intensive care unit admissions in Federal Medical Centre Umuahia south east Nigeria. Niger J Med 2012;21(1):70-73

18 Vukoja M, Riviello E, Gavrilovic S, et al. CERTAIN Investigators. A survey on critical care resources and practices in low- and middle-income countries. Glob Heart 2014;9(3):337-42

19 Chalya PL, Gilyoma JM, Dass RM, et al. Trauma admissions to the intensive care unit at a reference hospital in Northwestern Tanzania. Scand J Trauma Resusc Emerg Med 2011;19:61
20 Ibrahim NA, Ajani AWO, Mustafa IA, et al. Road traffic injury in Lagos, Nigeria: assessing prehospital care. Prehosp Disaster Med 2017;32(4):424-430

21 Punchak M, Mukhopadhyay S, Sachdev S, et al. Neurosurgical care: availability and access in low- and middle-income countries. World Neurosurg 2018;112:e240-e254

22 Kuo BJ, Vaca SD, Vissoci JRN, et al. A prospective neurosurgical registry evaluating the clinical care of traumatic brain injury patients presenting to Mulago National Referral Hospital in Uganda. PLoS One 2017;12(10):e0182285

23 Smart LR, Mangat HS, Issarow B, et al. Severe traumatic brain injury at a tertiary referral center in Tanzania: epidemiology and adherence to brain trauma foundation guidelines. World Neurosurg 2017;105:238-248

24 Gupta S, Khajanchi M, Kumar V, et al. Third delay in traumatic brain injury: time to management as a predictor of mortality. J Neurosurg 2019. Doi:10.3171/2018.8.JNS182182

25 Sekhon MS, Gooderham P, Toyota B, et al. Implementation of neurocritical care is associated with improved outcomes in traumatic brain injury. Can J Neurol Sci 2017;44(4):350-357 